University of Nebraska - Lincoln

DigitalCommons@University of Nebraska - Lincoln

Faculty Publications, Department of Psychology

Psychology, Department of

September 1992

\title{
One-trial backward excitatory fear conditioning transfers across contexts
}

Rick A. Bevins

University of Nebraska-Lincoln, rbevins1@unl.edu

John J. B. Ayres

University of Massachusetts, Amherst, joeayres@psych.umass.edu

Follow this and additional works at: https://digitalcommons.unl.edu/psychfacpub

Part of the Psychiatry and Psychology Commons

Bevins, Rick A. and Ayres, John J. B., "One-trial backward excitatory fear conditioning transfers across contexts" (1992). Faculty Publications, Department of Psychology. 150.

https://digitalcommons.unl.edu/psychfacpub/150

This Article is brought to you for free and open access by the Psychology, Department of at DigitalCommons@University of Nebraska - Lincoln. It has been accepted for inclusion in Faculty Publications, Department of Psychology by an authorized administrator of DigitalCommons@University of Nebraska - Lincoln. 
Behav. Res. Ther. Vol. 30 No. 5, pp. 551-554, 1992

Copyright (C) 1992 Pergamon Press Ltd. Used by Permission

\title{
One-trial backward excitatory fear conditioning transfers across contexts
}

\author{
RICK A. BEVINS and JOHN J. B. AYRES* \\ Department of Psychology, University of Massachusetts, Amherst, MA 01003, U.S.A.
}

(Received 9 October 1991)

\begin{abstract}
Summary--One path to human phobia may be one-trial backward fear conditioning. Human phobias transfer readily across contexts. However, animal studies of one-trial backward fear conditioning have yet to demonstrate such transfer. The present study sought to do so. It used a lick-suppression procedure with 84 naive male albino rats. Two conditioning contexts, designated $\mathrm{O}$ and $\mathrm{V}$, were crossed factorially with two test contexts, $\mathrm{O}$ and $\mathrm{V}$. Within each cell of the factorial design, rats received in the conditioning context either a single 12 sec tone backward paired with a single $4 \mathrm{sec} 1 \mathrm{~mA}$ shock or the same tone explicitly unpaired with shock. Fear of context and fear of tone were subsequently assessed in terms of the suppression of licking that they evoked. Test results suggested that (1) the rats discriminated between contexts $\mathrm{O}$ and $\mathrm{V}$, and (2) despite such discrimination, one-trial backward fear conditioning transfered across the two contexts. The results enhance the plausibility of one-trial backward fear conditioning as a source of human phobia.
\end{abstract}

This report deals with two questions of interest to students of human anxiety disorders. The first is whether the animal conditioning literature provides convincing evidence that a single Pavlovian conditioning trial can cause significant fear conditioning. The second is whether Pavlovian backward conditioning is a plausible source of human phobia.

With regard to the first issue, Sturgis and Scott (1984, p. 103) have argued that Pavlovian conditioning models of human phobias should be rejected in part because phobias often result from a single experience. According to these writers, there is little evidence in the experimental literature for one-trial Pavlovian fear conditioning. In contrast to Sturgis and Scott, we believe that there are numerous examples of one-trial fear conditioning in the animal experimental literature, including several reports from our own laboratory (Albert, 1990; Ayres, Haddad \& Albert, 1987; Burkhardt \& Ayres, 1978; Mahoney \& Ayres, 1976; Shurtleff \& Ayres, 1981; van Willigen, Emmett, Cote \& Ayres, 1987). The present results will add to that body of data.

With regard to the second issue, a number of writers have observed that human phobias are so widespread that theorists must consider broadening the theoretical pathways to fear acquisition rather than confining their attention to the obvious routes of Pavlovian forward delay and/or trace conditioning. Eysenck (1975), for example, suggested the possibility that backward conditioning might provide an additional path to human phobia. In backward conditioning procedures, the unconditioned stimulus (US) precedes the conditioned stimulus (CS), and thus the CS cannot predict US onset. Even so, evidence is mounting that backward fear conditioning procedures using a small number of trials can indeed establish measurable conditioned fear to the backward-paired CS (for a review, see Spetch, Wilkie \& Pinel, 1981). Again, the demonstrations from our own laboratory seem especially relevant because they were based on only a single backward conditioning trial (Albert, 1990; Ayres et al., 1987; Mahoney \& Ayres, 1976; Shurtleff \& Ayres, 1981; van Willigen et al., 1987). Moreover, in contrast to an earlier claim for one-trial backward excitatory fear conditioning (Keith-Lucas \& Guttman, 1975), these studies used white noise or tone as CSs, stimuli that are thought to have no particular biological relevance to the rat Ss.

One undesirable aspect of the existing evidence for one-trial backward excitatory fear conditioning, however, is that every demonstration so far has involved testing for conditioning to the CS in the same context in which the conditioning took place. Clearly, human phobias transfer readily across contexts. They are not limited to the specific context in which they were acquired. If one-trial backward fear conditioning is to be a plausible source of human phobia, then one must demonstrate such conditioning when the test context is discriminably different from the original training context. The present study sought to arrange this demonstration. In addition, it directly compared the strength of excitatory backward fear conditioning when the test context was the same as the conditioning context and when it was discriminably different from the conditioning context.

Like previous research, the present study measured fear of a backward-paired CS by giving it to thirsty rats licking a water tube. Suppression of licking evoked by the CS was taken as an index of backward conditioned fear. Suppression of licking evoked prior to CS onset was taken as an index of fear conditioned to the context.

\section{METHOD}

Subjects

The Ss were 84 experimentally naive male albino rats 90 days old on receipt from the Holtzman Company, Madison, Wisc. They arrived in two shipments about 5 months apart. There were 44 rats in the first shipment and 40 in the second. The rats were housed individually in suspended stainless steel cages in a room lighted $24 \mathrm{hr} /$ day and had $24 \mathrm{hr}$ access to food. Begining 1-2 days after arrival, each rat was handled for about 1 min on each of the 7 days before the experiment began.

*Author for correspondence. 
Apparatus

Two Gerbrands operant boxes were housed in ventilated $0.61 \mathrm{~m}$ cubes of $12.7 \mathrm{~mm}$ plywood lined with acoustical tile. These boxes served as two discriminably different contexts. The inside dimensions of one context, Box 0, were $23.2 \times 20.3 \times 19.5 \mathrm{~cm}$. The end walls were aluminum and the sides and top were clear Plexiglas. The floor was made of 18 stainless steel rods, $2 \mathrm{~mm}$ dia, mounted $1.3 \mathrm{~cm}$ apart. Box 0 was cleaned with tap water after each rat. The second context, Box V, had two metal plates inserted as false end walls. The insertion was such that these end walls formed a truncated V. Thus, at floor level, there was $5.3 \mathrm{~cm}$ between the plates, and at ceiling level there was $23.2 \mathrm{~cm}$. The floor was made of four stainless steel rods, $2 \mathrm{~mm}$ dia, mounted $1.3 \mathrm{~cm}$ apart. The side walls and top were clear Plexiglas. After each rat, Box V was cleaned with a solution of $20 \%$ distilled vinegar $(5 \%$ acidity) and $80 \%$ tap water.

Each box had in one side wall a $5.1 \times 1.3 \mathrm{~cm}$ horizontal slot giving access to a lick tube covered with heat shrinkable tubing save for its tip. The lick tube was attached to a bottle of tap water and to a Grason-Stadler drinkometer (Model E4690A-I) that recorded licks. The tip of the lick tube was centered in the slot about $5 \mathrm{~mm}$ outside the box. This position prevented all but tongue contacts.

Background lighting was provided by a $7.5 \mathrm{~W} 110 \mathrm{~V}$ frosted red bulb mounted $15 \mathrm{~cm}$ outside the far wall from the lick tube and $20 \mathrm{~cm}$ above the floor of the housing cube. The CS was an $86 \mathrm{~dB} 1000 \mathrm{~Hz}$ tone delivered through a $10 \mathrm{~cm}$ dia speaker mounted on the box lid. A high voltage, high resistance shock source provided a $4 \mathrm{sec} 1 \mathrm{~mA}$ grid shock US scrambled through a relay sequencing scrambler (Hoffman \& Fleshier, 1962). The metal plates in Box V were wired into the shock circuit.

A third box was used to hold each rat between exposures to the two contexts during lick training (see procedure). The inside dimensions of the holding box were 19.6 x $19.1 \times 18.5 \mathrm{~cm}$. The walls were wood painted with vertical black and white stripes about $1.9 \mathrm{~cm}$ wide. The floor was solid aluminum, and the lid was clear Plexiglas.

Procedure

Lick training. After 2 days of exposure to a $23.5 \mathrm{hr}$ water deprivation schedule, the rats received 4 days of lick training. On Day 1 , each rat was given access to the water bottle first in Box O, then in Box V. In each box, the 100th lick produced a 2 min dummy CS (no change from the rat's view). One minute after the end of the dummy CS, the rat in Box O was placed in the holding box. If there was a rat in Box V, it was returned to the colony and given access to water for $0.5 \mathrm{hr}$. The next rat was taken immediately from the colony and placed in Box O. The rat in the holding box was then placed in Box V. Thus, on Day 1 the cycle of placements was colony, O, holding box, V, colony. On Day 2, the cycle was reversed. Days 3 and 4 replicated Days 1 and 2 respectively.

Conditioning and testing. Following lick training was 1 day of conditioning and then 1 day of testing. Figure 1 shows the experimental design and assignment of rats to treatments. The figure shows that a factorial design was used in which the two conditioning contexts (Boxes $\mathrm{O}$ and $\mathrm{V}$ ) were crossed with the two test contexts $(\mathrm{O}$ and $\mathrm{V})$. Eighty of the 84 rats were assigned at random to the cells of the design. The extra 4 sets were assigned arbitrarily to the four cells shown in the right half of Fig. 1. Thus 40 rats were conditioned in Box O and 44 in Box V. In each context, half the rats received the tone CS backward paired with the shock US (BP condition). The remaining rats received the same tone explicitly unpaired with shock (EU condition). In the BP condition, the $4 \mathrm{sec} 1 \mathrm{~mA}$ shock US began $203 \mathrm{sec}$ into the session. At shock termination, the $12 \mathrm{sec}$ tone CS began. For 22 of the rats in the EU condition, the shock preceded the tone CS. In this explicitly unpaired backward (EUB) procedure, the 4 sec shock US began 213 sec into the session and the $12 \mathrm{sec}$ tone CS began $398 \mathrm{sec}$ into the session. For the remaining 20 rats in the EU condition, the tone preceded the shock. In this explicitly unpaired forward (EUF) procedure, the $12 \mathrm{sec}$ tone CS began $11 \mathrm{sec}$ into the session, and the $4 \mathrm{sec}$ shock US began 203 see into the session. The total session duration was $432 \mathrm{sec}$. The lick tube was absent during conditioning. [For a discussion of the validity of the EU control procedures, see Mahoney and Ayres (1976).]

As shown in Fig. 1, half the rats were tested in the same box in which they were conditioned (i.e. conditioned in $\mathrm{O}$, tested in $\mathrm{O}$, or conditioned in $\mathrm{V}$, tested in $\mathrm{V}$ ). The other half were tested in the box different from that in which they were conditioned (i.e. conditioned in $\mathrm{O}$, tested in $\mathrm{V}$, or conditioned in $\mathrm{V}$, tested in $\mathrm{O}$ ). The test procedure copied that of lick training except that a 2 min tone CS replaced the 2 min dummy CS and the rat was tested in just one box.

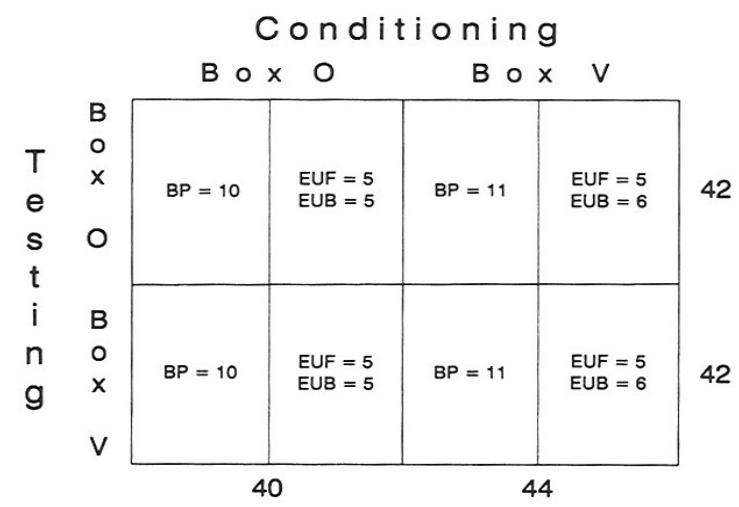

Fig. 1. Design of experiment. Numbers in the cells refer to the number of rats assigned to each condition. Abbreviations: $\mathrm{BP}=$ backward paired condition (tone immediately followed shock termination); EUF = explicitly unpaired forward condition (a long forward trace procedure); EUB = explicitly unpaired backward procedure (a long backward trace procedure). 
Dependent measures and data analyses. The following dependent measures were collected during lick training and testing: he time to complete the first 90 licks (latency to 90 licks), the time between licks 90 and 100 (pre-CS time), and the time between licks 100 and 110 (CS time). The longer the CS time, the greater the CS-evoked suppression, and the stronger the ear conditioned to the CS is assumed to be. CS time could not exceed the duration of the tone CS used in testing (i.e. 20sec). To maintain comparability of our results with those previously reported from this laboratory (Ayres et al., 1987; Van Willigen et al., 1987) and others (e.g. Kasprow, Cacheiro, Balaz \& Miller, 1982), we converted the dependent measures 0 logs (base 10), used parametric analyses of variance (ANOV As), and adopted a two-tailed rejection region of 0.05 .

\section{RESULTS}

Preliminary analyses found no difference between the two shipments of rats on any of the three dependent measures Fs $<$ I). Accordingly, the results from the two shipments were combined in subsequent analyses. Likewise the results of he two types of EU control (EUF and EUB) were combined into a single EU condition, as there was no significant difference between them on any of the dependent measures $\left(F_{S}<1.31\right)$.

Figure 2 shows the mean $\log$ CS times for BP and EU conditions when the conditioning and test boxes were the same and when they were different. The figure suggests that the mean $\log$ CS time in the BP condition was longer than that of the EU condition regardless of whether the test box differed from the conditioning box. A two-way ANOV A was used 0 test this impression. One factor was conditioning treatment (BP vs EU) and the other was type of test box (same vs different). The greater suppression to the tone CS in the BP condition as compared to the EU condition was confirmed 'Y a main effect of conditioning treatment $[F(1,80)=4.29]$. The main effect of test box type and the interaction of conditioning treatment with test box type were not significant $(F S$ $<1.38$ ). The main effect of conditioning treatment was lot complicated by a difference in the log pre-CS rates of licking. Those rates were similar for the BP and EU conditions $F=2.42$ ).

Figure 3 shows the mean log latency to 90 licks during testing. The figure suggests that the rats took longer to make he first 90 licks when the conditioning and test boxes were the same than when they differed $[F(1,82)=11.29]$. This fact shows clearly that the rats discriminated between the two contexts.

\section{DISCUSSION}

The major result of this study was that lick suppression evoked by a tone CS was greater when the tone had been backward paired with shock than when tone and shock had been explicitly unpaired. This tendency held regardless of whether the test and conditioning boxes were the same or were discriminably different. That the rats actually did discriminate between the two contexts is shown by the fact that they took longer to make their first 90 licks when the two contexts were the same than when the two contexts differed. Presumably, the latency to make the first 90 licks reflects fear conditioning to context. The shorter latency when the two contexts differed suggests less fear of the test context that differed from the conditioning context. We can conclude that onetrial excitatory backward fear conditioning can survive a discriminable change in context from conditioning to testing. This survival enhances the plausibility of one-trial backward excitatory conditioning as a source of human phobia. However, two caveats must be noted. First, although the two contexts clearly were discriminated, they obviously shared a number of identical elements. Perhaps if the differences between them were enhanced, backward excitatory fear conditioning would not survive. Second, although we have found statistically significant evidence for one-trial backward excitatory fear conditioning both here and in several other reports from this laboratory (Albert, 1990; Ayres et al., 1987; Mahoney \& Ayres, 1976; Shurtleff \& Ayres, 1981; van Willigen et al., 1987), none of those effects has been large. It is yet unclear whether these small effects simply reflect our ignorance about appropriate conditioning parameters or whether these effects are as large as they get. If the latter is true, then it is doubtful that effects so small could truly serve as a basis for human phobias.

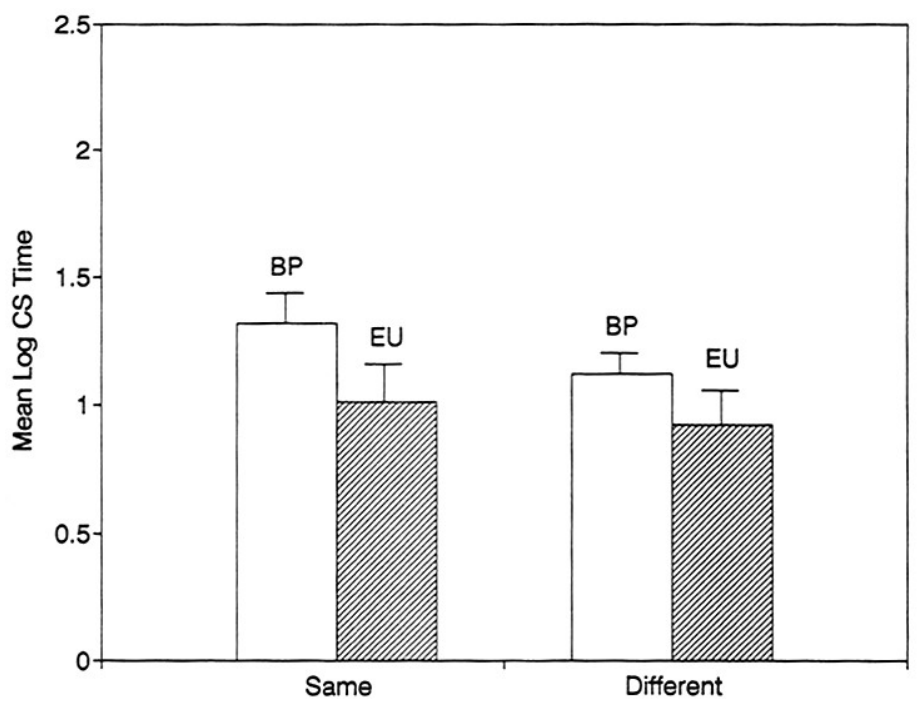

Fig. 2. Mean log (base 10) latencies to emit 10 licks in the presence of the test CS for backward paired (BP) and explicitly unpaired (EU) control groups. Vertical lines above the bars show 1 SEM. 


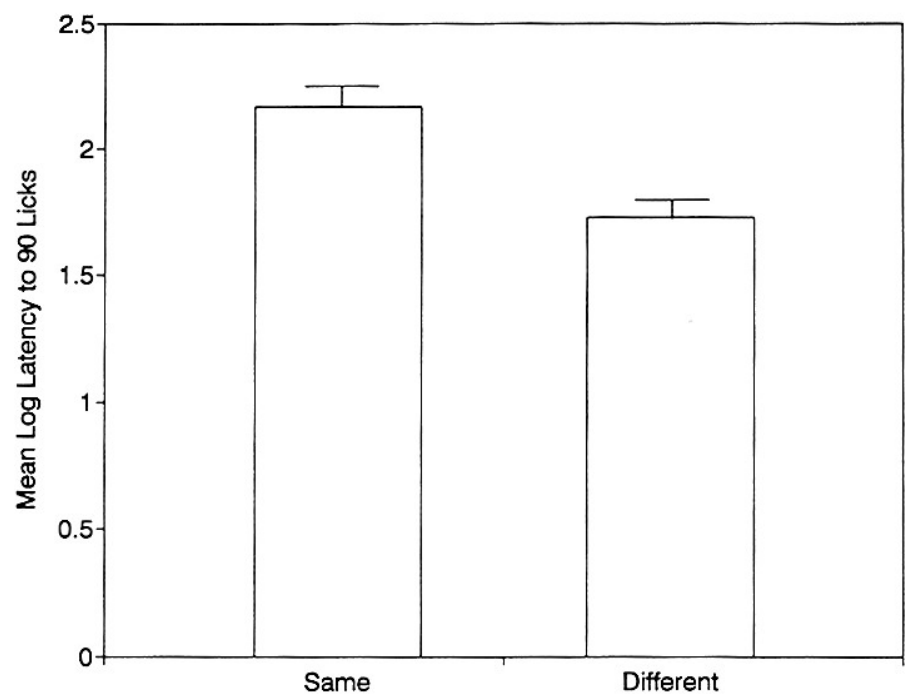

Fig. 3. Mean log (base 10) latencies to emit the first 90 licks in the test session. Vertical lines above the bars show 1 SEM.

Acknowledgements-This research was supported by Grant BNS 87-23173 from the National Science Foundation to John J. B. Ayres. We wish to thank Pat Wisocki for her advice about the manuscript.

\section{REFERENCES}

Albert, M. (1990). Conditioning to a compound CS and the observation of CS-elicited behavior in 1-trial simultaneous and 1-trial backward conditioning procedures. Unpublished doctoral dissertation, University of Massachusetts, Amherst.

Ayres, J. J. B., Haddad, C. \& Albert, M. (1987). One-trial excitatory backward conditioning as assessed by conditioned suppression of licking in rats: Concurrent observations of lick suppression and defensive behaviors. Animal Learning \& Behavior, 15, 212-217.

Burkhardt, P. E. \& Ayres, J. J. B. (1978). CS and US duration effects in one-trial simultaneous fear conditioning as assessed by conditioned suppression of licking in rats. Animal Learning \& Behavior, 6, 225-230.

Eysenck, H. J. (1975). A note on backward conditioning. Behaviour Research and Therapy, 13, 201. Hoffman, H. S. \& Fleshier, M. (1962). A relay sequencing device for scrambling grid shock. Journal of Experimental Analysis of Behavior, 5, 329-330.

Kasprow, W. J., Cacheiro, H., Balaz, M. A. \& Miller, R. R. (1982). Reminder-induced recovery of associations to an overshadowed stimulus. Learning and Motivation, 13, 155-166.

Keith-Lucas, T. \& Guttman, N. (1975). Robust-single-trial delayed backward conditioning. Journal of Comparative Physiology and Psychology, 88, 468-476.

Mahoney, W. J. \& Ayres, J. J. B. (1976). One-trial simultaneous and backward fear conditioning as reflected in conditioned suppression of licking in rats. Animal Learning \& Behavior, 4, 357-362.

Shurtleff, D. \& Ayres, J. J. B. (1981). One-trial backward excitatory fear conditioning in rats: Acquisition, retention, extinction, and spontaneous recovery. Animal Learning \& Behavior, 9, 65-74.

Spetch, M. L., Wilkie, D. M. \& Pinel, J. P. J. (1981). Backward conditioning: A reevaluation of the empirical evidence. Psychology Bulletin, 89, 163-175.

Sturgis, E. \& Scott, R. (1984). Simple phobias. In Turner, S. M. (Ed.), Behavioral theories and treatment of anxiety. New York: Plenum Press.

van Willigen, F., Emmett, J., Cote, D. \& Ayres, J. J. B. (1987). CS modality effects in one-trial backward and forward excitatory conditioning as assessed by conditioned suppression of licking in rats. Animal Learning \& Behavior, 15, 201-211. 